Rev. Hist., N²7, vol. 2, Julio-Diciembre 2020: 237-264

ISSN 0717-8832

https://doi.org/10.29393/RH27-17FESE30017

\title{
Figuraciones emergentes del espacio-tiempo: cronotopos del cuerpo y el aula en la educación chilena*
}

\section{Emergent figurations of space-time: chronotopes of the body and the classroom in}

\section{Chilean education}

\author{
Sergio Elórtegui Francioli: Orcid: https://orcid.org/0000-0003-3868-6514 ${ }^{* *}$ \\ Leticia Arancibia Martínez: https://orcid.org/0000-0003-3010-6765 ${ }^{* * *}$ \\ Andrés Moreira-Muñoz: Orcid: https://orcid.org/0000-0002-9136-1391 ${ }^{* * *}$
}

\section{RESUMEN}

Se propone el análisis histórico de la educación chilena teniendo en cuenta la perspectiva de cronotopo del cuerpo en el aula como una herramienta analítica que nos permite entender cómo se construye y ordena- y eventualmente se segrega- la forma más básica y orgánica de estar en sociedad. Nuestra hipótesis es que las desigualdades y la segregación han surgido en Chile desde sus propias aulas, moldeando los cuerpos, desde las prácticas estatales desde los inicios de la República hasta los procesos de apropiación y precarización de la educación por parte del modelo neoliberal actual. Nuestro objetivo es desarrollar una reflexión entre la evolución y el tratamiento de la persona desde la historia y la biopolítica, como un "cuerpo que aprende" en distintos contextos espacio-temporales. Se despliega aquí una crítica analítica del cronotopo del aula en Chile en relación con la naturaleza fenomenológica del cuerpo: i) el cuerpo en su dimensión biológica ii) el cuerpo ante el cuerpo del otro y iii) el cuerpo como sujeto ante sí mismo.

Palabras clave: Historia de la educación; modelo neoliberal; desigualdades educativas; biopolítica del cuerpo; escuela activa.

\section{ABSTRACT}

The historical analysis of Chilean education is proposed taking into consideration the chronotope perspective of the body in the classroom as an analytical tool that allows us to understand how the most

\footnotetext{
*Elaborado en el marco del proyecto Anillos ANID PIA SOC 180040 "GeoHumanidades y Biogeografías Creativas" (www.biogeoart.cl). Agradecimientos a Francisca Veas, colaboradora del proyecto, que proveyó la ilustración de la Exposición "Educasión Shilena". Y a Daniel Paiva del Instituto de Geografía y Planificación Espacial de la Universidad de Lisboa, que realizó constructivos comentarios en el proceso de revisión del artículo.

${ }^{* *}$ Doctor en Ciencias de la Educación, Pontificia Universidad Católica de Chile. Posdoctorante Proyecto Anillos ANID PIA SOC 180040, Pontificia Universidad Católica de Valparaíso. Email: kelortegui@hotmail.com.

*** Doctora en Sociología por la Université Catholique de Louvain, Profesora de la Escuela de Trabajo social de la Pontificia Universidad Católica de Valparaíso. Investigadora titular Proyecto Anillos ANID PIA SOC 180040. Email: leticia.arancibia@pucv.cl.

${ }^{* * * *}$ Doctor en Ciencias Naturales de la Universidad Erlangen-Nürnberg, Profesor Titular de la Pontificia Universidad Católica de Valparaíso, Instituto de Geografía. Email: andres.moreira@pucv.cl.
} 
basic and organic way of being in society is constructed and ordered - and eventually is segregated. Our hypothesis is that inequalities and segregation have arisen in Chile from their own classrooms, molding bodies, from state practices since the beginning of the Republic to the processes of appropriation and precariousness of education by the current neoliberal model. Our objective is to develop a reflection between the evolution and the treatment of the person from history and biopolitics, as a "body that learns" in different space-time contexts. An analytical critique of the classroom chronotope in Chile is displayed here in relation to the phenomenological nature of the body: i) the body in its biological dimension, ii) the body facing the body of the other, and iii) the body as a subject confronted to itself.

Keywords: History of education; neoliberal model; educational inequalities; biopolitics of the body; active school.

Recibido: septiembre 2019

Aceptado: Agosto 2020

\section{Introducción}

"Antes que nada, las pedagogías son relaciones" 1

Las cronotopías constituyen enunciados espacio-temporales que incluyen a las figuraciones sobre las crisis sociales, culturales y económicas ${ }^{2}$. En Chile, a partir del 18 de octubre de 2019, se hace patente la crisis social y se vuelve a los grandes movimientos sociales a partir del impulso estudiantil. Las protestas chilenas son el resultado de uno de los sistemas sociales más desiguales del mundo ${ }^{3}$. Iniciadas por estudiantes escolares, las protestas han alcanzado rápidamente a toda la sociedad, volviendo a las manifestaciones masivas que no se habían vivido desde el final de la dictadura.

Las protestas de los estudiantes no son nuevas: masivas manifestaciones ocurrieron en 2006, 2011 y 2017. Con pocos cambios reales, el sistema de educación neoliberal implantado durante la dictadura con el apoyo de la oligarquía y la influencia de Estados Unidos, es el pilar del mantenimiento de desigualdades en Chile ${ }^{4}$. Solo los ricos pueden asegurar su posición en sitios importantes de toma de decisiones, siendo la línea que separa la política de los negocios

\footnotetext{
1 Beier, Marshall y Raha, Sandeep. 2019. Cultivating an ethos: collegial co-discovery in a Children and Youth University, Children's Geographies № 1, Vol. 18, London, pp. 44-57.

2 Rodríguez Marino, Paula. 2018. “Emplazamientos y cronotopos en Historias mínimas y en Tierra adentro" en Núñez, Paula Gabriela; Núñez, Andrés; Matossian, Brenda; Tamagnini, Marcela; Odone Correa, María Carolina. AraucaníaNorpatagonia II: La fluidez, lo disruptivo y el sentido de la frontera. Viedma, Universidad Nacional de Río Negro. ${ }^{3}$ OCDE. 2020. Inégalité de revenu (indicateur).

4 Moreno-Doña, Alberto y Gamboa, Roberto. 2014. "Dictadura chilena y sistema escolar "a otros dieron de verdad esa cosa llamada educación", en Educar em Revista, № 51, Curitiba. Editora UFPR 51, pp. 51-66.
} 
realmente delgada, permitiendo los patrones continuos de acumulación y despojo desde las transformaciones estructurales de la dictadura ${ }^{5}$.

Actualmente en Chile, alrededor del $80 \%$ de los estudiantes formados en escuelas privadas pueden continuar estudios universitarios, mientras que solo el $44 \%$ de los estudiantes de escuelas subvencionadas y solo el $30 \%$ de los estudiantes de escuelas públicas llegan a las universidades ${ }^{6}$. Este es solo un punto que demuestra las altas desigualdades que configuran la sociedad chilena desde el sistema privatizado neoliberal implantado durante la dictadura, que básicamente no ha cambiado hasta nuestros días 7 .

En informes internacionales comparados, Chile alberga el mayor descenso en las últimas décadas $^{8}$. Pero esto es solo la punta del iceberg de un sistema intrínsecamente segregador en el que las desigualdades heredadas pasan de una generación a la siguiente. Los intentos por crear una escuela inclusiva y la educación como derecho social han sido sistemáticamente truncados ${ }^{9}$.

¿Cómo abordar un análisis de la situación que nos ilumine un sentido o visión para desenredar este nudo gordiano en que ha quedado atrapada nuestra educación? Proponemos analizar esta dinámica histórica desde la categoría del cronotopo. Abordarlo desde esta perspectiva es un desafío, ya que "en las subculturas, como las aulas, los cronotopos son a menudo desordenados, complicados, incompletos, múltiples y competitivos y pueden variar en diferentes situaciones dentro de la misma aula ${ }^{10}$.

Nuestra hipótesis es que las desigualdades y la segregación han surgido en Chile desde sus propias aulas, promovidas por las prácticas estatales desde los inicios de la República y que luego se han potenciado con regímenes de violencia y desigualdad, hasta nuestros días.

Nuestro objetivo es desarrollar una reflexión entre la evolución y el tratamiento de la persona como un "cuerpo que aprende" en distintos contextos espacio-temporales. Se

\footnotetext{
${ }^{5}$ Núñez, Iván. 1984. Las transformaciones educacionales durante el régimen militar. Santiago, PIIE.

${ }^{6}$ Sistema único de Admisión DEMRE. 2016. https://demre.cl/estadisticas/documentos-2016-compendio-p2016.

${ }^{7}$ Carillo Nieto, Juan José. 2010. E"I neoliberalismo en Chile: entre la legalidad y la legitimidad, entrevista a Tomás Moulián" en Perfiles Latinoamericanos, №35, Vol. 18, México

${ }^{8}$ Altinok, Nadir; Angrist, Noam; Patrinos, Harry Anthony. 2018. Global Data Set on Education Quality (1965-2015) World bank Group. Education Global Practice Group January 2018. http://documents.worldbank.org/curated/en/706141516721172989/pdf/WPS8314.pdf. Ver también "La desigualdad de ingresos ha aumentado en casi todos los países de la OCDE en las últimas tres décadas. En 2014, los países de la OCDE con el nivel más alto de desigualdad de ingresos fueron Chile, México y los Estados Unidos" (OCDE 2016); Times Press. 2019. Why Chile's SATs Have Become the New Frontline of Inequality Protests. New York. Recuperado de https://time.com/5770308/chile-student-protests/ (Consultado 13 de Julio de 2020).

${ }^{9}$ Corvalán, Javier y García-Huidobro, Juan Eduardo. 2015. "La educación de mercado en Chile y su propuesta de superación", Cuaderno de Educación № 66, Santiago, pp. 1-16.

10 Bloome, David; Beierle, Marlene; Grigorenko, Margaret; Goldman, Susan. 2009. "Learning over time: Uses of intercontextuality, collective memories, and classroom chronotopes in the construction of learning opportunities in a ninth-grade language arts classroom", in Language and Education, Vol.23, №4, London, pp. 313-334.
} 
despliega aquí una crítica analítica del cronotopo del aula en Chile en relación con la naturaleza fenomenológica del cuerpo: i) el cuerpo en su dimensión biológica, ii) el cuerpo ante el cuerpo del otro y iii) el cuerpo como sujeto ante sí mismo.

\section{El cronotopo como fenomenología interpretativa de las desigualdades educativas}

Los cronotopos pueden definirse como prácticas construidas socialmente que están estrechamente interconectadas en el tiempo y el espacio ${ }^{11}$. La definición operativa de espacio y lugar es aquella que hace que el espacio se convierta en un lugar cuando, con el tiempo, se asocia a posibilidades socialmente significativas ${ }^{12}$. En este sentido, el giro espacial permea actualmente tanto la visión eminentemente espacial como la temporal-histórica ${ }^{13}$. El cronotopo del cuerpo en el aula nos permite entender cómo se construye y ordena -y eventualmente se segrega- la forma más básica y orgánica de estar en sociedad, es decir, la escuela: "creado a partir de las antiguas palabras griegas kronos y topos, que significan tiempo y espacio/lugar, Mikhail Bajtín ideó el cronotopo tanto para examinar los patrones espacio-temporales que caracterizan los géneros literarios como para desarrollar un marco para el análisis cultural del espacio-tiempo"14. Recientemente, la investigación educativa ha mostrado un interés creciente en este concepto ${ }^{15}$. Siguiendo a Bajtín, este artículo se basa, al igual que trabajos precedentes ${ }^{16}$ en la suposición de que el espacio y el tiempo son construcciones sociales interdependientes en lugar de realidades dadas independientes ${ }^{17}$.

El cronotopo, unidad espacio-temporal, emerge como un concepto expresivo objetivo, indisoluble y formal. En el tiempo, se cruzan cuerpo y aula, haciéndose visibles para el espectador y apreciables desde el punto de vista formal y estético.

\footnotetext{
11 Idem.

12 Kumpulainen, Kristiina; Mikkola, Anna; Jaatinen Anna-Mari. 2014. "The chronotopes of technology-mediated creative learning practices in an elementary school community", en Learning, Media and Technology, Vol.39, №1, Hesinki, pp. 53-74.

${ }_{13}$ Withers, Charles W. J. 2009. "Place and the "Spatial Turn" in Geography and in History" en Journal of the History of Ideas Vol. 70, № 4, pp. 637-658. http://www.jstor.org/stable/20621915; Massey, Doreen. 2005. For Space. New York, SAGE Publications Ltd.

${ }^{14}$ Bajtín, Mijaíl. 1989. Teoría y estética de la novela. Madrid: Taurus; Bajtín, Mijaíl. 1990. Estética de la creación verbal. México, Siglo xxi Editores; Holquist, Michael. 1982. "Bakhtin and Rabelais: Theory as praxis", in Boundary 2, Durham, pp.5-19.

${ }^{15}$ Brown, Raymond y Renshaw, Peter. 2006. "Positioning Students as Actors and Authors: A Chronotopic Analysis of Collaborative Learning Activities," en Mind, Culture and Activity Vol.13, №3, pp. 247-259.

${ }^{16}$ van Eijck, Michiel y Roth, Wolff Michael. 2010. Towards a chronotopic theory of "place" in place-based education, en Cultural Studies of Science Education, №4, Vol. 5, New York, pp. 869-898.

${ }^{17}$ La noción de cronotopo que Bajtín extrapola de la física y se desarrolla en "Las formas del tiempo y el cronotopo en la novela" (Bajtín 1989), expresa el carácter indisoluble del espacio y el tiempo, que, concebido en relación con el movimiento y la materia de los cuerpos, se configuran como sus propiedades. Por lo tanto, el tiempo puede ser una coordenada espacial: la cuarta dimensión del espacio. Para Bajtín, es a partir de la función del nodo cronotopo, que la novela puede articularse como tal, donde, a partir de esto, los cuerpos (personajes), las situaciones y las realidades cumplen su función lírica.
} 
Es el cuerpo como ente histórico, inmerso en el cronotopo del aula, el que finalmente se convierte en el hecho encarnado que nos permite evidenciar y comprender las desigualdades educativas. En relación a la escuela como si fuera una novela, es precisamente esta dimensión nodal y formal del espacio-tiempo del aula, "cronotopía del aula" vivida por los sujetos, la que nos facilita confrontarla a los razonamientos espacio-temporales construidos históricamente. De alguna forma el aula física -construida con lo vivo y no vivo- viaja y vive en el tiempo presente e histórico a la vez. $Y$ es tal vez en este escenario, de las "formas del tiempo construidas" (topogénesis) donde la obra de Bajtín, y este "constructo" bio-psico-social, ha tenido más impacto ${ }^{18}$. La atención histórica al cronotopo del aula en Chile es una herramienta que revela la forma más básica y radical respecto a cómo una sociedad construye al sujeto. La forma cronotópica en que el aula se configura es un espejo que naturaliza las diferencias, desatenciones y precauciones, invisibles pero a plena vista, que tiene el Estado con sus ciudadanos.

\section{Metodología}

Esta investigación recoge la teoría dialógica del cronotopo aportada por Bajtín y se esfuerza por conceptualizar las unidades de análisis según dicha teoría dentro del marco teórico que conlleva una investigación de carácter histórico. Esta conceptualización obedece a la comprensión de unidades tratadas como fenómenos dialógicos ${ }^{19}$.

El concepto de cronotopo es aún emergente y muchos de los trabajos que lo han utilizado lo hacen de forma heurística más que como una herramienta metodológica ${ }^{20}$. Sin embargo los aportes de Ritella y colaboradores proponen su uso de forma sistemática ${ }^{21}$. De esta propuesta, nuestro trabajo reinterpreta las características discursivas del material del espacio-tiempo como unidad de análisis (material-discursive features of spacetime) que se construye a partir de la interconexión entre los aspectos materiales, sociales y semióticos del espacio-tiempo ${ }^{22}$, relacionando las representaciones con simbolismos, considerando el espacio-tiempo cronotópico como una cápsula de fenómenos intersubjetivos factible de analizar.

\footnotetext{
18 Muntañola, Josep. 2007. Las Formas del Tiempo I: Arquitectura, educación y sociedad. Badajoz. España. Ed. @becedario.

${ }^{19}$ Säljö, Roger. 2009. "Learning, theories of learning, and units of analysis in research". Educational Psychologist, $\mathrm{N}^{\circ}$ 44, Vol. III, North Carolina, pp. 202-208.

20 Rajala, Antti; Hilppö, Jaako; Lipponen, Lasse; Kumpulainen, Kristiina. 2013. "Expanding the chronotopes of schooling for the promotion of students' agency", en n O. Erstad, \& J. Sefton-Green (Eds.). Identity, community, and learning lives in the digital age, Cambridge, MA: Cambridge University Press, pp. 107-125.

${ }^{21}$ Ritella, Giuseppe; Rajala, Antti; Renshaw, Peter. 2020. "Using chronotope to research the space-time relations of learning and education: Dimensions of the unit of analysis". Learning, Culture and Social Interaction, (article in press). 22 Ritella, Giuseppe y Ligorio, María Beatrice. 2016. "Investigating chronotopes to advance a dialogical theory of collaborative sensemaking", in Culture \& Psychology, № 22, Vol. II, Aalborg, pp. 216-231; van Eijck, Michiel y Roth, Wolff-Michael. 2010. "Towards a chronotopic theory of place in place-based education" en Cultural Studies of Science Education, N 5, Vol. IV, New York, pp. 869-898.
} 
En el caso de esta investigación el discurso se recoge a partir de los relatos e información histórica de diversas fuentes construidas a partir de documentos del Museo de la Educación de Chile y trabajos referidos a la historia de la educación. De esta información recogida y analizada sobre los relatos de las aulas en Chile desde comienzos del siglo XVII a mediados del siglo XIX se logró caracterizar los diferentes cronotopos de las aulas en relación a cómo el tiempoespacio y el cuerpo de los sujetos interaccionó como fenómeno. En una segunda fase, desde mediados del siglo XIX al XX, resaltan eventos históricos que cambiaron radicalmente el sentido de la educación escolar, especialmente la época de la Dictadura.

Hablar de escuela es hablar del control del espacio y del tiempo, estas dimensiones son constitutivas y consustanciales a ella. Supuestamente la escuela como tal reposa únicamente en estas dos dimensiones, clausurando al sujeto respecto del tiempo y espacio social ${ }^{23}$ :

"La organización de un espacio en serie fue una de las grandes mutaciones técnicas de la enseñanza elemental. Permitió sobrepasar el sistema tradicional (un alumno que trabajó durante unos minutos con el maestro, mientras que el grupo confuso de los que esperan permanece ocioso y sin vigilancia). Al asignar lugares individuales ha hecho posible el control de cada cual y el trabajo simultáneo de todos. Ha organizado una nueva economía del tiempo de aprendizaje. Ha hecho funcionar el espacio escolar como una máquina de aprender, pero también de vigilar, de jerarquizar, de recompensar" ${ }^{24}$.

Los espacios educativos se asocian más comúnmente a un espacio cerrado. Históricamente, la ausencia de estos espacios se consideraba parte del subdesarrollo. Mientras que en las culturas tradicionales o aborígenes, la educación tuvo lugar en un espacio relacional dentro de la comunidad, la sociedad occidental basó toda su estructura en la segregación de los estudiantes en espacios cerrados ${ }^{25}$. Si bien hoy la tecnología inunda estos espacios educativos con deseos de innovación, el aula sigue congelada bajo un orden que fragmenta los tiempos y espacios desatendiendo las cualidades orgánicas e interrelacionales de estas dimensiones. La organización espacio-tiempo puede generar cambios en la enseñanza y aprendizaje basada en el uso pedagógico de la tecnología ${ }^{26}$, las aulas de Chile, abiertas a la tecnología, siguen aferradas

\footnotetext{
${ }^{23}$ Dantier, Bernard. 1999. Séparation ou désintégration de l'école? Ed. L'Harmattan, Montreal.

${ }^{24}$ Foucault, Michel. 1998. Vigilar y castigar. Madrid, Siglo XXI, p. 15.

25 Peters, Michael y Besley, Tina. 2014. "Social Exclusion/Inclusion: Foucault's analytics of exclusion, the political ecology of social inclusion and the legitimation of inclusive education", en Open Review of Educational Research, vol.1, №1, Cambridge, pp. 99-115.

${ }^{26}$ Ritella, Giuseppe, \& Ligorio, Maria Beatrice. 2016. "Investigating chronotopes".
} 
a la idea de una enseñanza frontal centrada en los contenidos y que es evidenciada desde los patrones de discurso docente ${ }^{27}$.

Este espacio críptico que sintetiza la idea de la escuela y nos separa de "un exterior", no es fenomenológicamente neutro, por el contrario, se construye históricamente y se sumerge de manera especular, respondiendo históricamente a la mirada de su tiempo en una forma cronotópica. En lo relativo a la escuela se ha sobredimensionado la arquitectura de la razón y el conocimiento -logos- como foco de la enseñanza. Pero la fenomenología nos habla de una "razón encarnada", una razón hecha materia en un cuerpo-razón-emoción que "es" y percibe con todos sus sentidos. Este cuerpo como "materia" es la clave de una nueva coordenada para entender el aula. Si el tiempo es la cuarta coordenada del espacio, el cuerpo-materia es la quinta coordenada que construye el fenómeno del aula: cronotopía del cuerpo en el aula. Este análisis cronotópico del aula se enriquece al ponerlo en su contexto histórico, lo que nos permite el desarrollo de una mirada compleja del fenómeno.

El tiempo y espacio de la escuela en Chile ha sido permeable al decurso histórico en la que esta se ha inscrito. El núcleo particular del aula ha evolucionado de diversas formas desde la conquista española en adelante. Desde las leyes de Indias, edictos, reformas y contrarreformas se llega a lo que hoy se reconoce como la escuela chilena. La trayectoria histórica, mirada en perspectiva y como contexto determinante al espacio y tiempo del aula, nos ilumina sobre los cambios paradigmáticos sobre el aprendizaje en Chile. Dentro de estas aulas se han formado y transformado generaciones de chilenos. Pero la naturaleza de las transformaciones supera con creces los conocimientos curriculares que ahí se entregaron. De una u otra forma el niño aprende también en ella su posición entre los otros, su valor y proyecta una mirada sobre el contexto social y el mundo.

Para entender cómo el cronotopo histórico del aula se ha interrelacionado con el cuerpo de los sujetos, es necesario una breve comprensión de los hitos cronotópicos que la historia de Chile le ha entregado a su escuela. Desde esta comprensión se percibe con mayor claridad cómo se configuró y evolucionó este lugar. Dividiremos en dos períodos la historia de la educación, esto debido a que el cuerpo en el cronotopo del aula es cualitativamente distinguible.

\footnotetext{
27 González, Jorge; Preiss, David; San Martín, Ernesto. 2008. "Evaluando el discurso docente: desarrollo de un modelo de Rash a partir de la evidencia audiovisual de profesores chilenos de primer ciclo de educación básica en el área de lenguaje" en Revista Iberoamericana de Evaluación Educativa, № 1, Vol II, Madrid, pp. 138-147; Preiss, David. 2011. "Patrones instruccionales en Chile: La Evidencia de la Evaluación Docente”, en Manzi, J., González, R., (Eds.) La Evaluación Docente en Chile, Santiago: MIDE UC, Pontificia Universidad Católica de Chile, pp. 209-212; Radovic, Darinka \& Preiss, David. 2010. "Patrones de discurso observados en el aula de matemática de segundo ciclo básico en Chile" en Psykhe, № 19, Vol. II, Santiago, pp. 65-79.
} 


\section{Fase histórica I: siglos XVII-XIX}

Los hitos cronotópicos comienzan en el siglo XVII, en el marco de la colonia española y bajo la administración de los nuevos territorios y "los nuevos sujetos" por la corona. Bajo la mirada de un dominio impregnado en el catolicismo español de la época del siglo anterior, con un "rey monje" celebrado en El Escorial y la inquisición en pleno apogeo, la evangelización del "salvaje" se hizo urgente para convertirlo en un buen católico y así evitar los tormentos del infierno. De la misma manera, los hijos de los colonos tenían que ser atendidos para que no cayeran en una vida lujuriosa y mundana con el mismo propósito que los anteriores. Menos que todos estos, las mujeres, incluidas las hijas de familias numerosas, con suerte aprendieron a escribir su nombre ${ }^{28}$. Así, las primeras escuelas del Reino de Chile, bajo el alero de los conventos, eran en el mejor de los casos, establos o cobertizos acondicionados donde "los niños pobres aprendieron a leer, escribir y contar, y la doctrina cristiana" ${ }^{29}$. Durante el siglo XVIII, la cronotopía de la escuela pública no sufrió grandes variaciones. Algunas ilustres excepciones como la Academia de San Luis (1796), creada por Manuel de Salas con influencias de la iluminación europea, se adelantaron a su tiempo; pero su impacto, dirigido a familias ricas, fue menor, tomando el contexto nacional deteriorado. Hasta el primer cuarto del siglo XIX, la escuela pública seguía pareciendo un pesebre con instrucción precaria y para unos pocos, dejando una gran masa de excluidos fuera de toda instrucción ${ }^{30}$.

\section{Fase histórica II: siglos XIX-XX}

Abarca desde la segunda mitad del siglo XIX al XX. Con la independencia y la conformación de la república, el discurso hacia la escuela toma una fuerza renovada asumiendo la educación como uno de los ideales liberales e igualitarios por excelencia. En la carta fundamental de 1833, el Estado, a través de un Ministerio de Instrucción Pública, asume el rol paternal sobre la educación. Pero aunque esto sí se tradujo en un aumento de escuelas, su impacto fue solo para los sectores altos y la élite masculina republicana ${ }^{31}$. Durante este siglo la escuela se expresó como un mecanismo de segregación que acentuó la diferencia de clases privilegiando la formación de la aristocracia regente, promoviendo una alfabetización básica para el resto y así alejarlos de la "barbarie" 32 . El problema de la educación siguió centrado en el tema de la cobertura y accesibilidad para unos pocos, acentuando la falta de equidad social. En lo que

\footnotetext{
28 Labarca, Amanda. 1939. Historia de la Enseñanza en Chile, Santiago, Prensa de la Universidad de Chile.

${ }^{29}$ Frontaura, José. 1892. Noticias históricas sobre las escuelas públicas de Chile a fines de la era colonial, Santiago, Imprenta Nacional.

30 Orellana Rivera, María Isabel. 2010. Una mirada a la escuela chilena: entre la lógica y la paradoja, Santiago, Ed. SM, $198 \mathrm{pp}$.

${ }^{31}$ Jaksic, Iván y Serrano, Sol. 2000. "El poder de las palabras: la iglesia y el estado liberal ante la difusión de la escritura en el Chile del siglo XIX", Historia, vol.33, Santiago, pp.435-460. Versión On-line ISSN 0717-7194.

${ }^{32}$ Orellana Rivera, María Isabel. 2010. Una mirada a la escuela chilena: entre la lógica y la paradoja, Santiago, SM.
} 
respecta al espacio del aula pública, la Ley Orgánica de Instrucción Primaria de 1860 y luego la promulgación de su obligatoriedad en 1920 que constituyó al Estado Docente, responsabilizó al gobierno, entre otras cosas, en la construcción de espacios dignos, mobiliario y textos para la enseñanza. A esto se sumaron esfuerzos en la preparación docente, principalmente a través de las Escuelas Normales o preceptoras; la primera de las cuales se inauguró en 1842 teniendo como su primer director a Domingo Faustino Sarmiento, intelectual argentino que impactaría en la educación y la política con el ideologema: civilización y barbarie ${ }^{33}$. Las Escuelas Normales funcionaron hasta 1974 y en la formación docente se caracterizaron por una epistemología germana de la educación. Aún con sus reconocidos beneficios, la enseñanza impartida por dichos profesores era más bien rígida, directiva, frontal y profundamente vertical; lo que diseñó la atmósfera de un aula que aún es familiar a comienzos del siglo XXI.

El primer cuarto del siglo XX dio a luz un salto político cualitativo con la Constitución de 1925. Su primer mayor impacto a la educación fue la separación del Estado y la Iglesia donde la escuela, por lo menos en el papel, podía escindirse de la performatividad del discurso religioso y conocer nuevos conceptos como el humanismo liberal. Es a la sombra de este cambio constitucional que ocurrió quizás el primer esfuerzo de tipo cualitativo por "pensar" la educación y que quizás, adelantado a su época, pudo haber impactado la cronotopía del aula escolar. La reforma educacional de 1928 fue profundamente influenciada por John Dewey, naturalista y educador norteamericano, cuya postura paidocéntrica era la de una escuela activa, puertas afuera, centrada en el hacer y no solo en el aprender por aprender; postura claramente reñida con la tradición normalista. Sin embargo, esta postura que hoy parece tan obvia, no prosperó en el contexto de la carga histórica y problemas sociales muy superiores a la reflexión pedagógica. Recién a fines de siglo, a través del legado de los CAI (centros académicos independientes) y las universidades, se retomará con las ciencias de la educación la discusión sobre los paradigmas en los cuales se funda la educación en Chile.

La educación en el siglo XX se centró en dos problemas básicos "cobertura y equidad" 34 . Las reformas educacionales de los primeros tres cuartos de siglo, tanto en su contenido como objetivos tienen como meta ponerse a tono con el proceso de desarrollo nacional basado en la industrialización y el desarrollo del mercado interno ${ }^{35}$. Hasta 1973 la educación se llevó a cabo desde el poder central configurando el Ilamado Estado Docente. El Estado, por tanto, norma y reglamenta en materia educativa y se responsabiliza en ampliar el servicio bajo la administración del Ministerio de Educación Pública con la idea principal de darle a la educación

\footnotetext{
${ }^{33}$ Alam, Florencia. 2016. "Civilización/barbarie en los manuales de historia del secundario", en Nómadas. Revista Crítica de Ciencias Sociales y Jurídicas, $\mathrm{N}^{\circ} 16$, Buenos Aires, pp. 1-9.

${ }^{34}$ Cox, Cristián. 1985. Hacia la elaboración de consensos en política educacional: actas de una discusión, Santiago, CIDE; Picazo, Inés. 2010. "La metamorfosis de la regulación pública en la educación escolar en Chile: hacia un estado post-neoliberal”, en Revista Pensamiento Educativo, Vols. 46-47, №1, Santiago, pp. 63-91.

35 Picazo, Inés. 2010. “La metamorfosis de la regulación pública en la educación escolar en Chile.
} 
una función democratizadora. Este sistema se caracterizó por la centralización, burocratización y verticalismo. La Reforma educacional de 1965 liderada por el ministro Juan Gómez Millas, buscaba "reducir la deserción escolar para garantizar un nivel cultural mínimo para la población. Esta reforma introdujo diferentes niveles en la educación: parvulario, primario y medio, así como el ciclo común y el medio diferenciado, los que concluirían eventualmente con el ingreso del estudiante al nivel superior, el universitario." ${ }^{36}$ El Decreto NA 27.953, en su Primer Artículo, establecía que a partir de 1966, el primer año de Humanidades pasaba a ser séptimo año básico de la (nueva) "Educación General Básica que desde esta Reforma durará ocho años". Con ella la original Educación Primaria se extendió dos años y cambió la mirada hacia una más profesionalizante de la docencia.

Con el golpe militar de 1973 el Estado Docente es cambiado por un Estado Subsidiario donde el principio de la libertad de enseñanza se trastoca como libertad de generar negocio con la educación ${ }^{37}$. El Estado Subsidiario descansa en el pensamiento neoliberal impulsado por los Chicago Boys y este será el alma de la reforma educativa militar. En la práctica se aseguró la educación primaria básica a todos los niños y respecto de la secundaria y superior, esta será un privilegio al que solo se accede pagando o reembolsando sus costos a la agencia que la imparta. Los militares en conjunto con sus aliados civiles, se reservaron el derecho de elaborar los planes y programas y evaluar la educación. Actividad que más que ser una mirada de reflexión pedagógica es más bien un control de mercado sobre la calidad del servicio y de represión ideológica.

La educación post dictadura no hizo grandes cambios al modelo neoliberal aun cuando hay diferencias en la interpretación del modelo. La imposibilidad de llegar a acuerdos políticos en el Congreso para reformar el legado militar y la tendencia neoliberal mantuvieron en vigencia la Ley Orgánica Constitucional de Enseñanza hasta el año 2009. El sistema escolar se basó en la dimisión del Estado y la liberación a ultranza de las fuerzas del mercado ${ }^{38}$. El Estado se concentró en la ejecución de acciones focalizadas (Programa 900 escuelas, Liceo para todos) pero manteniendo la municipalización, siguiendo la lógica subsidiaria. Desde las investigaciones de las CAl surge la crítica sobre otros aspectos de la igualdad educativa quizá más determinantes que el factor democratizante de la enseñanza y su masificación, esta es sobre

\footnotetext{
${ }^{36}$ Memoria Chilena. 2018. El Ministerio de Educación y el Estado docente (1927-2006). Reforma Educacional iniciada en 1965. http://www.memoriachilena.gob.cl/602/w3-article-97353.html.

37 Picazo, Inés. 2010. "La metamorfosis de la regulación pública en la educación escolar en Chile: hacia un estado post-neoliberal" en Pensamiento Educativo, № 46, Valdivia, pp. 63-91.

38 "el sistema escolar chileno fue organizado en torno a la dimisión del rol del Estado, la centralidad de lo privado, la implementación de subsidios a la demanda y la generación de fuertes políticas de rendición de cuentas, ha potenciado y profundizado fenómenos de segregación educativa, reducción de la libertad de elección y movilización social en el país, produciendo transformaciones en las estructuras, procesos y resultados educativos"; Villalobos, Cristóbal y Quaresma, María Luisa. 2015. "Sistema escolar chileno: características y consecuencias de un modelo orientado al mercado, en Convergencia, Revista de Ciencias Sociales, UAEM, № 69, pp. 63-84.
} 
"la igualación de los resultados internos del proceso educativo" ${ }^{39}$. La educación no es de la misma calidad para todos y los resultados lo manifiestan ${ }^{40}$. Ante este panorama de desigualdad y exclusión, a partir de 2014 se desarrolla una reforma educativa que intentará cambiar el sistema educativo con las leyes de Inclusión escolar (20.485), Nueva Educación Pública (21.040) así como en los planes y programas para la formación ciudadana y educación cívica (20.911), entre las principales ${ }^{41}$. Sin embargo en su aplicación y práctica concreta, resistencias en sectores conservadores, así como la existencia de un mercado de la educación en Chile, se continúa en un terreno de inequidad y segregación que sigue definiendo entre otras cosas la cronotopía del aula.

¿Cómo definir una cronotopía del aula en este segundo periodo tan convulsionado políticamente? Más allá del ideario político e ideológico y el lenguaje subyacente, la batalla cronotópica del aula no fue tan innovadora respecto de un cambio de paradigma. El cambio consistió -en palabras de Gómez Catalán referidas a la reforma de 1928-en pasar de: "un aula pobre y derruida con un profesor adusto y ceremonioso y un aprendizaje memorístico" 42 a un aula moderna llena de TICS, con coloridos libros de contenidos pre-envasados y estandarizados, distribuidos por unas pocas preeminentes editoriales y por lo general con un profesor adusto y ceremonioso y eminentemente un aprendizaje memorístico. Evidentemente, los cambios en general no fueron profundos ni rompieron los principios heredados desde el primer periodo.

\section{Biopolítica y Cronotopías del aula y el cuerpo}

La mirada histórica permite distinguir la inscripción social del cuerpo, lo que significa que este no es un a priori de orden biológico, que sometería "las diferencias sociales y culturales a la

\footnotetext{
39 Picazo, Inés. 2010. "La metamorfosis... "

40 OECD (2017) OCDE Revisiones de recursos escolares: Chile 2017.

${ }^{41}$ Nos referimos a la Reforma educativa realizada a partir de 2014, en el gobierno de Michelle Bachelet Jeria, entre cuyas leyes y normativas principales mencionamos: Ley de Nueva Educación Pública (Ley 21.040, 2017); Ley de inclusión escolar, que impone desde lo normativo elementos de no discriminación, gratuidad (Ley 20.845, 2015) y la generación de las condiciones para que los niños, jóvenes y adultos que asisten a colegios con subvención del Estado reciban una educación de calidad, garantizando la educación como un derecho, sin que "la capacidad de pago, rendimiento académico u otros tipos de discriminación arbitraria" (Ley 20.845) los excluyan. Además, se generan los Planes y Programas para Formación ciudadana, estableciéndose la exigencia para los establecimientos educacionales con reconocimiento oficial, que, al año 2019, se incluya formación ciudadana y educación cívica (Ley 20.911, 2017), con el propósito de brindar "a los estudiantes la preparación necesaria para asumir una vida responsable en una sociedad libre y de orientación hacia el mejoramiento integral de la persona humana, como fundamento del sistema democrático, la justicia social y el progreso. Asimismo deberá propender a la formación de ciudadanos, con valores y conocimientos para fomentar el desarrollo del país, con una visión del mundo centrada en el ser humano, como parte de un entorno natural y social" (Ley 20.911, artículo único).

42 Caiceo Escudero, Jaime. 2010. Luis Gómez Catalán y su aporte a las políticas educacionales en la Reforma Educacional de 1927 en Chile, en Revista Electrónica Diálogos Educativos №19, pp. 19-35; Gómez Catalán, Luis. 1928. Mensaje que el Jefe del Departamento de Educación Primaria dirige a los padres de familia de Chile, Santiago, Imprenta La Nación.
} 
primacía de lo biológico (o mejor dicho, de un imaginario biológico), de naturalizar las desigualdades de condiciones justificándolas a través de observaciones "científicas": el peso del cerebro, el ángulo facial, la fisiognomía, la frenología, el índice encefálico, etc. Una imaginación frondosa le hace preguntas al cuerpo" ${ }^{43}$ y así es como se instala la idea de raza, de superioridad o inferioridad racial, de primacía o jerarquía social asociado. Diferente de esta visión es la consideración que el cuerpo es sobre todo una construcción social que media representaciones, actitudes y conductas -frente o a través de este- que da cuenta de su inscripción histórica. Por lo tanto ha sido moldeado, disciplinado, significado y representado de acuerdo a la sociedad y el medio en que se encuentra.

Cuando hablamos de cuerpo nos referimos a aquello que testimonia y participa, reproduciendo formas de vida y significaciones de las relaciones, pero también como espacio de confrontación y resistencia ante el orden instituido. Desde la arena de la sociología y la antropología los estudios se concentrarán en las técnicas corporales, como el artículo de Marcel Mauss ${ }^{44}$ considerando los gestos codificados para obtener eficacia simbólica; la gestualidad del cuerpo desde la interacción, la comunicación y la mente, que se expresó en las corrientes del interaccionismo simbólico, con G. H. Mead y desde la escuela de Chicago que atenderá a la corporeidad asociada a las características funcionales de diferentes actores ${ }^{45}$.

Para entender el cuerpo y su carga histórica, social y cultural destaca el trabajo de Norbert Elías, con su obra "La civilisation des moeurs" ${ }^{46}$, donde los modales son expresiones valoradas como avance o retroceso cultural y conquistas civilizatorias. De este modo, pone el foco en la cultura gestual, su modelación y significación distinguiendo "el carácter social y cultural de muchas de las conductas más triviales y más íntimas de la vida cotidiana" ${ }^{47}$. También su obra "La Société de cour" ${ }^{48}$, analiza y distingue la cultura de la corte francesa como "laboratorio en el que nacieron y a partir del que se difundieron las reglas de cortesía" que se fueron instalando en la sociedad europea en términos de "convenciones de estilos de vida, de educación de los sentimientos, de las intervenciones corporales, del lenguaje y, sobretodo, de lo que compete al campo del externum corporis decorum" ${ }^{49}$. De este modo, la civilidad implicará saber vivir como la clase dominante.

Más asociada a esta línea de análisis se encontrarán el modo en que Foucault analiza el cuerpo desde su inscripción en las relaciones de poder, que fija el límite, la transgresión, los

\footnotetext{
${ }^{43}$ Le Breton, David. 2011. La sociología del cuerpo, Buenos Aires, Nueva visión, p. 16.

${ }^{44}$ Mauss, Marcel. 2013. Sociologie et anthropologie, Paris, PUF.

45 Cisneros Sosa, Armando. 1999. "Interaccionismo simbólico, un pragmatismo acrítico en el terreno de los movimientos sociales”. Sociológica № 41, pp. 104-126.

${ }^{46}$ Elías, Norbert. 1973. La Civilisation des moeurs, Paris, Calmann-Lévy.

${ }^{47}$ Le Breton, David. 2011. La sociología del cuerpo. Buenos Aires, Nueva visión, p. 21

${ }^{48}$ Elías, Norbert. 1974. La Société de Cour, Paris, Calmann-Lévy.

${ }^{49}$ Le Breton, David. 2011. La sociología...
} 
tabúes y prohibiciones, pero también el espacio potencial de liberación, según sea la época histórica y la episteme que prime en cada periodo. De este modo el cuerpo está sujeto a las dinámicas del poder, sometido "a las técnicas y las tácticas de dominación" ${ }^{50}$, inscrito en el campo político: "Pero el cuerpo está también directamente inmerso en un campo político; las relaciones de poder operan sobre él [como] una presa inmediata; lo cercan, lo marcan, lo doman, lo someten a suplicio, lo fuerzan a unos trabajos, lo obligan a unas ceremonias, exigen de él unos signos"51.

Para Foucault, el poder sobre el cuerpo se irá afinando históricamente a través de diferentes dispositivos y técnicas de poder, donde la disciplina 'fabricará' individuos, "a la vez como objetos y como instrumentos de su ejercicio" ${ }^{52}$, en espacios como la escuela, la cárcel o la clínica. A través de la disciplina los sujetos se vuelven útiles y en el contexto de la expansión del capital y la producción que dan forma al capitalismo, se buscará su multiplicación y administración como vidas y como población. Para Foucault ${ }^{53}$, "El cuerpo, en una buena parte, está imbuido de relaciones de poder y de dominación, como fuerza de producción; pero en cambio su constitución como fuerza de trabajo solo es posible si se halla prendido en un sistema de sujeción (...). El cuerpo solo se convierte en fuerza útil cuando es a la vez cuerpo productivo y cuerpo sometido". Así, se desarrollarán "métodos que permiten el control minucioso de las operaciones del cuerpo, que garantizan la sujeción constante de sus fuerzas y les imponen una relación de docilidad-utilidad, es a lo que se puede llamar las 'disciplinas'. Muchos procedimientos disciplinarios existían desde hace largo tiempo atrás, en los conventos, en los ejércitos, también en los talleres. Pero las disciplinas han llegado a ser en el transcurso de los siglos XVII y XVIII unas fórmulas generales de dominación" 54 .

"Ha habido, en el curso de la edad clásica, todo un descubrimiento del cuerpo como objeto y blanco de poder. Podrían encontrarse fácilmente signos de esta gran atención dedicada entonces al cuerpo, al cuerpo que se manipula, al que se da forma, que se educa, que obedece, que responde, que se vuelve hábil o cuyas fuerzas se multiplican" ${ }^{55}$.

El surgimiento del cuerpo bajo esta consideración vendrá de la mano del nacimiento de la biopolítica, donde la emergencia de la vida en el campo de la política se da con la superación de su concepción divina, o como "el polo opuesto de la muerte, sobre la cual el soberano extiende su autoridad, para convertirse en un efecto de la acción política. La vida como algo

\footnotetext{
${ }^{50}$ Foucault, Michel. 1998. Vigilar y castigar, Madrid, Siglo XXI, p. 147.

51 Ibíd., p. 32.

52 Ibíd., p. 175.

53 lbíd.

54 Ibíd., p. 141.

55 Ibíd., p. 140.
} 
que puede ser producido, administrado y gestionado por el Estado; en suma, la vida como resultado de la intervención y planificación humana sobre un 'medio ambiente'"56.

De este modo se instala una economía política del cuerpo que se articula con la nueva biopolítica que administra poblaciones, para una utilización económica del cuerpo, por lo tanto productiva. Esto dará forma a lo que Foucault denomina "la tecnología política del cuerpo"57, que operará para controlar el "buen empleo del cuerpo, que permite un buen empleo del tiempo" ${ }^{58}$, el que se irá segmentando cada vez más para que el cuerpo se ajuste -a través de la disciplina- de acuerdo a los ritmos impuestos bajo una concepción lineal del tiempo ${ }^{59}$.

En las dos fases históricas previamente enunciadas, se recurre a tres unidades de análisis que responden a la naturaleza fenomenológica del cuerpo en el cronotopo del aula histórica: i) el cuerpo en su dimensión biológica, ii) el cuerpo ante el cuerpo del otro y iii) el cuerpo como sujeto ante sí mismo. Estas unidades ya no solo están referidas a hechos en una línea de tiempo histórica, sino que se construyen desde una teoría cronotópica de análisis, tal como lo adelanta Ritella sobre ideas de análisis referidas a nuevos marcos holísticos de investigación integrados ${ }^{60}$.

\section{El aula y el cuerpo en su dimensión biológica}

En el cronotopo del aula del primer periodo, el cuerpo ante el cosmos como materialidad y como organicidad, tuvo una concepción particular y fue objeto de concesiones por parte del aula. La mirada es la de tratar de conocer cómo se articuló este cuerpo con el tiempo y el espacio del aula construida. Rápidamente se puede detectar en la literatura que la valía material del individuo, a excepción del que ostentase algún título nobiliario, no era claramente diferente que la otorgada a otros bienes materiales, incluido mujeres en su totalidad y niños (adultos incompletos) en formación, aunque se tratase de hijos de los privilegiados. En 1803 el oidor Manuel de Irigoyen al visitar los establecimientos educacionales del reino por encargo del Gobernador señala: "se advirtió falta de comodidad para los jóvenes, extraordinario desaseo, en términos que algunos más parecían establos que escuelas" ${ }^{61}$. Por otra parte, se ha sugerido que la España absolutista ignoró avaramente la educación de sus colonias y esto se tradujo en la precariedad de la escuela: "troncos o asientos muchas veces traídos por los mismos niños uno que otro pupitre y escaso material de apoyo fueron la regla general" ${ }^{62}$. Hasta 1850 las

\footnotetext{
${ }^{56}$ Castro-Gómez, Santiago. 2010. "Siglo XVIII: El nacimiento de la biopolítica” en Tabula Rasa No 12 Bogotá, p.3.

57 Foucault, Michel. 1998. Obra citada, p. 33).

58 lbíd., p. 156).

59 Lefebvre, Henri. 1992. Rhythmanalyse, Paris, Éditions Syllepse.

60 Ritella, Giuseppe; Rajala, Antti; Renshaw, Peter. 2020. "Using chronotope to research the space-time relations of learning and education: Dimensions of the unit of analysis" en Learning, Culture and Social Interaction. Disponible en: https://doi.org/10.1016/j.Icsi.2020.100381 (Consultado el 20 de junio de 2020).

${ }^{61}$ Labarca, Amanda. 1939. Historia de la Enseñanza en Chile, Santiago, Editorial Universidad de Chile.

62 Orellana Rivera, María Isabel. 2010. Una mirada a la escuela chilena, Santiago, SM, p. 79.
} 
descripciones del mobiliario ausente o miserable, niños de pie o sentados en el suelo y los turnos para escribir en la única mesa de la escuela eran lo regular ${ }^{63}$. Mirado este escenario desde el presente pudiera parecer indignante, pero desde esta dimensión cronotópica en ese contexto, se abre una mirada de época hacia el cuerpo menos consiente de la diferencia respecto a otras corporalidades como la animal. Así como hoy un buey en la yunta puede pasar tiempo indeterminado de pie soportándola sin mayor reparo del observador, la reflexión sobre los tiempos corporales humanos "adecuados" para estar de pie o sentado aprendiendo o con el estómago vacío, contaban con escasa reflexión o argumentos de esa época (éticos o científicos) para ser debatidos. El tema del cuerpo vivo se incorporó a una mirada de reciedumbre y precariedad natural sin mayor oposición o cuestionamiento. Esta mirada por cierto no fue privativa de la educación; el trabajo y la justicia sobre el cuerpo recién tuvieron un eco a mediados del siglo XX. Aun así el tiempo de permanencia en el aula, en contraste al de hoy, era considerablemente más corto. "Regularmente las horas de asistencia eran en la mañana de 8 a 11 y en la tarde de 2 a $5^{\prime \prime 64}$. Pero lo que parecía una sana concesión, en realidad no liberaba al cuerpo, ya que al niño o joven se le requería como fuerza trabajadora en algún contexto público o doméstico. Recién en 1850 el Estado se concentró en reforzar los tiempos que hasta ese momento eran manejados por el criterio del profesor. Se introdujo el reloj que determinó la duración de las clases y las pausas...y debuta la famosa "campana" para marcar dichos cambios. Este cambio redefinió cualitativamente la escuela como cronotopía; la convirtió en una dimensión del espacio-tiempo "regular y regulada"65.

El segundo periodo trajo algunas consideraciones ergonómicas respecto a la comodidad de los alumnos: trajo asientos. Pero lo que no ha traído son las consideraciones sobre cuánto tiempo debe pasar un cuerpo sentado sin consecuencias físicas y mentales. Situación que es aún más grave si para tal "actividad" tampoco hay consideraciones para diferencias etarias. En el presente el horario escolar es similar desde $1^{\circ}$ básico a $4^{\circ}$ medio. Los bancos para sentarse tuvieron una evolución interesante (obs. Museo de La Educación de Chile). Ya en 1820 se incorporó el banco lancasteriano, que consistía en un mesón largo con un tablón para sentarse; su diseño era apto para contener aulas con muchos alumnos (100 o más) poniéndolos en corridas uno detrás de otro. El primer banco era para los más aventajados y así hasta llegar a los últimos al fondo del salón. Solo en 1860 aparecieron los primeros pupitres, no muy diferentes a los anteriores, pero que contenían tintero y un espacio interior para contener libros. En este mismo periodo apareció el papel ya que hasta ese momento los alumnos

\footnotetext{
${ }^{63}$ Egaña, María Loreto. 2000. La educación primaria popular en el siglo XIX en Chile: una práctica de política estatal. Dirección de Bibliotecas, Archivos y Museos, LOM Ediciones, Santiago de Chile.

${ }^{64}$ Frontaura, José. 1892. Noticias históricas sobre las escuelas públicas de Chile a fines de la era colonial, Santiago, Imprenta Nacional.

${ }^{65}$ Dantier, Bernard. 1999. Séparation ou désintégration de l'école? Ed. L’Harmattan, Montreal.
} 
manejaban pizarras individuales. Para 1900 aparece el pupitre alemán que incorporaba el respaldo al "tablón" original. Al parecer alguien se percató de que los tiempos escolares podrían ser un tanto extensos para esa posición corporal.

Respecto al tiempo, las escuelas preceptoras de influencia alemana incorporaron un quiebre al encierro en el aula -que hasta ese momento solo contaba con los recreos (1850)-; las clases de educación física que se consideraban como parte de una educación saludable para el cuidado e higiene del cuerpo. Claro está que estas seguían el mismo patrón de enseñanza normalista con ejercicios repetitivos y en orden militar.

En relación a una deconstrucción del aula bajo una mirada de aprendizaje experiencial, el único intento de cambio paradigmático se basó en el pensamiento de Dewey: "La buena enseñanza depende del mundo puertas afuera, porque ahí es donde ocurre la vida, la real" 66 . La reforma de 1928 sostenía una pedagogía activa, donde la escuela "nueva" debía transformarse de un auditorio a un laboratorio y taller; en el cual los alumnos en el hacer y no en el repetir y memorizar, se convirtieran en entusiastas ciudadanos que aplican sus conocimientos con iniciativa. Sin embargo esta reforma quedó en el anecdotario, pues el aula construida desde la epistemología reinante no tenía espacio para un cambio de esa envergadura. Durante este periodo el cuerpo en el aula no tuvo mayores cambios espaciales a excepción de los bancos individuales de mediados del siglo XX y la incorporación de las TICS a principios del XXI y como si fuéramos hacia atrás, los tiempos de permanencia en el aula se hicieron cada vez más extensos con la incorporación de la Jornada Escolar Completa. Las consecuencias físicas, psicológicas y sociales de esta cronotopía aún están por estudiarse.

\section{El aula y el cuerpo frente al cuerpo del otro}

En el primer periodo, el espacio-tiempo social del estar con un "otro" para aprender, contenía particularidades discriminantes que hoy iniciarían inmediatos cuestionamientos éticos y seguras demandas. El mismo oidor Manuel de Irigoyen señaló en su informe de 1803 referido a las aulas de Santiago: ... "y en una (aula) noté un negro que se hallaba entre los alumnos" 67. Durante este periodo y acentuado en la colonia, la escuela era uno más de los organismos del Gobierno para separar en una escala los diferentes valores humanos asignados a los sujetos. La escuela fue formalmente una institución para la segregación. Hubo prohibición absoluta hasta la primera mitad del siglo XIX de que se admitiera en las escuelas a "negros y zambos" ${ }^{68}$.

\footnotetext{
66 Rivkin, Mary. 1998. "Happy Play in Grassy Places": The Importance of the Outdoor Environment in Dewey's Educational Ideal", in Early Childhood Education Journal, Vol. 25, No. 3, Pittsburgh, p. 28.

67 Labarca, Amanda. 1939. Historia de la Enseñanza en Chile, Santiago.

${ }^{68}$ Frontaura, José. 1892. Noticias históricas sobre las escuelas públicas de Chile a fines de la era colonial. Imprenta Nacional, Santiago de Chile.
} 
La educación del "reino" era "blanca, católica y masculina". La detección de las diferencias del cuerpo del otro, ya sea de género, color, costumbres o modos respecto de la regularidad dominante, era considerada una carencia o una "incompletitud" de lo que la divinidad creara como hombre. Por lo que educar lo que no puede llegar a ser completo es inequívocamente una aberración a la visión de esta sociedad, donde religión y Estado son una simbiosis. La situación de la mujer fue particularmente interesante. Su figura, puesta frente a la educación de la época, no tenía cabida. Según Labarca ${ }^{69}$ las niñas en el siglo XVII, aun siendo de familias principales, no gozaban del privilegio de las letras, y las que asistían al monasterio de las clarisas o agustinas lo hacían para el aprendizaje de actos de devoción y prácticas domésticas para el servicio de sus maridos ${ }^{70}$. Como reflejo de la visión contemporánea idealizada de la mujer en la iglesia -"virgen y santa"- cualquier instrucción que pudiera alejarla de este ideal, como entregarle argumentos para expresar pensamiento disidente, también fue considerado una aberración; por lo que las niñas no vieron las aulas hasta mediados del siglo XIX donde se comenzó a articular la escuela para "niñas" donde también aquí se sistematizó lo que una niña "debía aprender", acogiendo la herencia histórica y organizándose para la reproducción de roles tradicionales, expresándose una división sexual del trabajo ${ }^{71}$. Estas instituciones instalaron una mirada estereotipada: "de señoritas", imaginario que tuvo continuidad bajo la mención de "niñas", o "femenino" de los establecimientos que fueron preservando los regímenes de la biopolítica ${ }^{72}$ que operaban sobre los gestos, las conductas, las tecnologías y las formas de presentación impuestas al cuerpo de las niñas y las mujeres en la educación.

¿Y para los que sí asistían a la escuela pública? José Zapiola en su crónica "Recuerdos de treinta años"73 señala que el aula estaba dividida en dos secciones según la clase social a la que pertenecía el niño. Los distinguidos a los lados del maestro y atrás los menos favorecidos. Esta visión no se cuestionó y tuvo adeptos hasta fines del siglo XIX. Era lógico que los niños con diferentes costumbres, vocabulario y hábitos de aseo traídos de sus hogares no se debían mesclar en una escuela a la cual tenían "derecho" a asistir". En el presente la escuela, como reproductora social en Chile, ha resuelto el mismo problema separando a los niños a través de

\footnotetext{
69 Labarca, Amanda. 1939. Historia de la Enseñanza en Chile, Santiago.

70 Labarca, Amanda. 1939. Historia de la Enseñanza en Chile, Santiago. Editorial Universidad de Chile.

${ }^{71}$ Tahon, Marie Blanche. 1999. "Le micro-ondes, le privé et le domestique: rapports sociaux de sexe", en Recherches sociologiques, Vol.30, № 3, Ottawa, pp. 87-114; Arancibia, Leticia; Soto, Pamela; González, Andrea. 2016. Imaginarios sociales y biopolítica en la escuela: la mujer como cuerpo del delito. Cinta de moebio № 55, pp. 29-46. www.moebio.uchile.cl/55/arancibia.html

72 Foucault, Michel. 2007. Nacimiento de la Biopolítica. Curso en el Collège de France: 1978-1979, Buenos Aires, Fondo de cultura económica.

73 Díaz Cid, César. 2013. "Recuerdos de Treinta años (1810-1840) de José Zapiola: el sujeto que litiga con la historia y con los modelos tradicionales de representación autobiográfica" en Anales de Literatura Chilena. Santiago, N19, pp. 27-39; Zapiola, José. 1872. Recuerdos de treinta años (1810-1840). Colección: Biblioteca Nacional de Chile, Santiago.

${ }^{74}$ Orellana Rivera, María Isabel. 2010. Una mirada a la escuela chilena: entre la lógica y la paradoja, Santiago, SM.
} 
un criterio de accesibilidad económica. Ahora ya no están en la misma sala, están en diferentes escuelas.

Es en este periodo de corte piramidal en el aula, al igual que en el resto de las cosas, que la cronotopía del cuerpo frente a otro se manifiesta en una particular visión ontológica del ser humano. Creado de forma estanca y con su lugar definido por orden divino, su deber en adelante sería reconocer las diferencias y actuar en concordancia. Cualquier instrucción no tuvo como objetivo nivelar esta realidad, sino por el contrario acentuarla incluso de forma patente al interior del aula. En este sentido la visión de Locke $^{75}$ sobre las posibilidades infinitas del ser humano de ser lo que quiera ser o la de Rousseau de una sociedad libre e igualitaria expuesta en "El Contrato Social" 76 fueron demoradas en su aterrizaje en el aula de Chile. Aun cuando la naciente república se apresuró a consignarlas en el discurso del derecho público a la educación por Camilo Henríquez: "Es, pues, de necesidad que se arbitren medidas para asegurar la majestad de los derechos del pueblo y facilitarles mayores destinos a fin de aumentar el número de escuelas y obligar a los padres de familias pobres que destinen sus hijos primeramente a leer, escribir y contar"77.

"Primero había que disciplinar". Durante el segundo periodo, aún en la búsqueda de cobertura y equidad, el aula entró en una fuerte consonancia con los eventos políticos y transformaciones sociales e ideológicas. Pero tal vez donde la tolerancia de un "otro distinto" entró en crisis de forma más evidente fue en el contexto de violencia y transformaciones educacionales neoliberales luego del golpe militar del 11 de septiembre de 1973 en Chile. Conociendo el decurso de gobiernos totalitarios durante el segundo periodo, la historia reciente es profundamente ilustrativa para entender el aula desde la perspectiva cronotópica de estar con otros.

La relación con el otro distinto en la escuela durante la reciente dictadura fue realizado a través de la exclusión de ese otro en dos vías, una exclusión política, expulsando cualquier expresión de ciudadanía en la escuela, imponiendo un régimen disciplinario totalitario; y una exclusión social y económica, segregando a quienes no tienen cómo financiar la educación.

En una relación de mutua implicación, la violencia vino primero. Desde el golpe militar las instituciones educacionales pasaron a tener dependencia de los organismos militares, desde allí se ejerció un control férreo de la educación que disciplinó y volvió dóciles los cuerpos para

\footnotetext{
75 Tarcov, Nathan. 1984. Locke's Education for Liberty, Chicago, U of Chicago Press.

${ }^{76}$ Rousseau, Jean-Jacques. 2003. El contrato social o Principios de derecho político. Buenos Aires, Losada.

77 Santini, Benoit. 2012. "Traducciones y difusión de las ideas liberales, emancipadoras e ilustradas en los escritos del chileno Camilo Henríquez (1769-1825): defensa de las libertades, lucha por la independencia." En Rev. Historie(s) de l'Amerique latine, Paris. Vol. 7; Orellana Rivera, María Isabel. 2009. Cultura, ciudadanía y sistema educativo: cuando la escuela adoctrina. Dirección de Bibliotecas, Archivos y Museos - Museo de la Educación Gabriela Mistral, Santiago, LOM Ediciones.
} 
que se desarrollara cualquier experimento, como las transformaciones educacionales neoliberales del régimen militar. Estas transformaciones "tendrán como idea de base la introducción del mercado como mecanismo de regulación y disciplinamiento"78.

Desde el golpe de Estado se instaló una dinámica disciplinaria tanto de las modulaciones del cuerpo, como de las ideas ${ }^{79}$. Y era el gesto cotidiano en el aula el que se veía implicado porque a través de la vía de decretos prohibía cualquier forma de organización estudiantil o expresión colectiva de estudiantes, así como de profesores y profesoras. A través del conjunto de circulares y disposiciones, el Ministerio de Educación usó "su poder rector para imponer, a través de estos mecanismos burocráticos, normas específicas que regularon la educación de los alumnos en el logro de los objetivos autoritarios" ${ }^{80}$. Estos establecieron restricciones que se aplicaban al control de la información, la prohibición en el uso de libros y textos de estudio, el adoctrinamiento acerca de derechos humanos, así como la prohibición en la participación de cursos relacionados con la realidad nacional, entre otras, que dan cuenta del "control militar sobre la función educativa, control ideológico, control y promoción de valores patrios, control de organizaciones educacionales y otras relativas al campo educativo" ${ }^{11}$. El espacio de la escuela a través de estas disposiciones, en tanto establecimiento educacional debía regirse bajo una autoridad militar directa y bajo ella se ubicará la autoridad del director cuyas facultades serán las de realizar un intenso control y vigilancia, así como denuncia de los comportamientos que no se ajustaran a lo indicado por la junta militar de gobierno ${ }^{82}$. Asimismo, la tarea de disciplinar y asegurar la autoridad llevaba aparejada la función de delatar a colegas y denunciar a estudiantes. Es así como hubo alumnos y docentes que fueron sacados de las aulas por efectivos militares para ser detenidos, torturados y desaparecidos ${ }^{83}$. El cronotopo en este período busca

\footnotetext{
78 Salvat, Pablo 2001. "La lucha por la reconciliación en Chile: una aproximación desde la dialéctica del reconocimiento y la ética dialógica", en Lira, Elizabeth; Loveman, Brian; Mifsud, Tony y Salvat Pablo (ed.) Historia política y ética de la verdad en Chile, 1891-2001. Reflexiones sobre la paz social y la impunidad, Santiago. LOM ediciones, p. 70.

79 Magendzo, Abraham \& Gazmuri, Consuelo. 1984. "El control autoritario expresado en las circulares del Ministerio de educación en el periodo 1973-1981" en Núñez I. 1984 Las transformaciones educacionales bajo el régimen militar. Santiago, PIIE.

${ }^{80}$ Magendzo A. y Gazmuri C. op cit, p. 3.

81 Arancibia Martínez, Leticia. 2011. "El imaginario autoritario en la escuela secundaria durante la transición democrática en Chile", en Revista Análisis, $\mathrm{N}^{\circ}$ 12, Vol. I, pp. 97-119. Disponible en: https://revistas.upr.edu/index.php/analisis/article/view/10774

82 Magendzo A. y Gazmuri C. op cit, p. 3: Estas facultades consideraban: "atribuciones disciplinarias para suspender alumnos, profesores, auxiliares o administrativos que no acaten sus disposiciones;(...) efectuar investigaciones, sumarios internos a fin de determinar grados de responsabilidad (...) en relación a faltas cometidas; solicitar la intervención de la autoridad militar,(...) para solucionar problemas originados o en desarrollo (...); no permitir la creación de organismos internos, (...) y dar oportuna cuenta de su creación clandestina; exigir en forma perentoria y permanente, tanto a docentes como a educandos, la puntualidad y la presentación personal y el uso correcto de las tenidas".

${ }^{83}$ Magendzo A. y Gazmuri C. op cit, p. 9
} 
naturalizar la jerarquía, la dominación y la disciplina de los cuerpos y las ideas reforzando un imaginario autoritario en la escuela ${ }^{84}$.

A partir del disciplinamiento y la violencia, la instalación del modelo neoliberal en las aulas desplegará otra vía de exclusión: la exclusión social y económica, separando a los grupos sociales y sus costumbres en escuelas separadas de acuerdo con la accesibilidad mediada por los recursos económicos de la familia. Así, en la imposibilidad de las clases sociales menos privilegiadas de acceder a las escuelas de élite por un tema de costo, el problema quedó resuelto. Ahora el niño por lo general ve dentro de la escuela a otros niños similares en hábitos, lenguaje y colores. Los únicos intentos de confrontar habitus distintos ocurrieron durante el gobierno de Salvador Allende en el cual se incorporaron niños de la clase obrera a la educación privada; experiencia piloto que tuvo resultados contradictorios. Durante la dictadura y continuando con el retorno a la democracia, la tendencia neoliberal que marcó la escuela acentuó cada vez más la brecha social mediada por una educación primaria diferencial en su calidad y luego con el acceso a la educación secundaria y superior restringida por su costo. El resultado en esta dimensión es una sociedad profundamente segmentada por la inequidad y las diferencias en la calidad de la educación. Pero no es solo la diferencia social sino la lesión ética que implicó el utilitarismo, como fue expresado por el economista y ex ministro de Hacienda Hernán Büchi, quien criticó la inclusión del tema de los derechos humanos en el currículum escolar, basado en la inexistencia de un consenso social sobre determinados valores; en ese caso, sostuvo Büchi, el Estado no puede impulsar estos valores sin un riesgo: el de "manipular el perfil y los valores del cuerpo social, convirtiéndose en un ejercicio más del constructivismo social"85.

\section{El aula y el cuerpo como sujeto frente a sí mismo}

La escuela como formadora tiene un objetivo principal (explícito o no): ¿qué valor agregado se le dará al individuo que asiste a ella? O dicho de otra forma: ¿qué quiere la escuela, en representación del Estado, poner dentro de este sujeto? ¿Conocimientos, ideas, costumbres, valores? Si es así, no cualquier conocimiento o idea; los que sean útiles a su sociedad y por ende a sí mismos. Pero en este orden preciso. Para el primer periodo cronotópico de la escuela la libertad de pensamiento u objeción de conciencia eran impensables. En los primeros estertores del Reino de Chile la primera mirada formativa hacia los sujetos fue catequizar el alma para "la ciudad de Dios" a como diera lugar. Ilustrativa es la historia del padre Lope de Landa (1610) en Concón, que en juicio ante la Real Audiencia de Chile en el caso del desalojo de nativos, dijeron de él: ... “los despobló y quemó sus chozas y los llevó al valle de Quillota con ánimo y

\footnotetext{
${ }^{84}$ Arancibia op. cit.

${ }^{85}$ Ruiz Schneider, Carlos. 2012. La República, El Estado y el Mercado en Educación, en Revista de Filosofía, vol.68, Santiago, pp. 11-28.
} 
determinación de que estuvieran reducidos junto a la iglesia para administrarles los santos sacramentos" ${ }^{\prime 86}$. En un primer momento la escuela, como reflejo de esta mirada eclesial "inflamada", incorporó en su currículum la enseñanza de los ritos, la devoción, los rezos y las características de un vasallo obediente y piadoso. Hablando de la lógica colonial. ...“la escuela era el instrumento para conocer a Dios, para evangelizar al indio bárbaro, para evitar que los hijos de la iglesia se acercaran a una vida lasciva y profana" ${ }^{87}$.

En una segunda dimensión y hasta hoy -con énfasis en los periodos dictatoriales-la misión de la escuela se concentró en la "formación para la guerra", real o ficticia. Gran parte del tiempo o transversal a este, el acento siempre estuvo en inflamar el corazón de valores patrios; amor a la bandera, himnos, íconos y personajes y actos heroicos fueron la tónica. Este patriotismo siempre alcanzó su mayor sentido en la concepción de un "yo (chileno) contra un otro (no chileno)"; esto que parece obvio tuvo su praxis en el siglo de las guerras en Chile: emancipación, Guerra del Pacífico y Civil del 91 entre otras. La performatividad de este discurso formador de soldados se hizo realmente fuerte en la escuela republicana del siglo XIX, reapareciendo durante las dictaduras militares posteriores. Sigue Camilo Henríquez en la "Aurora de Chile" (1813), respecto del objetivo de la creación de más escuelas: "de este modo tendremos mejores artesanos, gente mejor dispuesta para el ejército y todos estaríamos mejor instruidos en nuestra sana moral". Referido al Estado Docente de mediados del siglo XIX, se enfatiza la escolarización como principal instrumento del desarrollo de la identidad nacional y construcción de ciudadanía ${ }^{88}$.

Otro aspecto cronotópico interesante de la época fue la forma de disciplinar al "cuerpo" para corregir una falta en la conducta o de conocimiento, expresado magistralmente en el dicho: "la letra con sangre entra". Lo regular fue el castigo físico o la ridiculización pública. Este ejercicio docente, lejos de ser ocasional, contó con una creativa industria del diseño punitivo: punteros, palmetas y celdas portátiles tuvieron su auge, junto a las prácticas de exposición pública de las faltas, en el siglo XVIII y XIX. "Los instrumentos más usados eran el chicote y el guante (látigos de distintas formas). Disponían también de la palmeta, instrumento que infundía terror entre los discípulos dado el dolor que provocaba" ${ }^{89}$. Este ejercicio era frecuentemente delegado a los propios alumnos, donde el profesor les designaba como verdugos de los rezagados; castigo que en ocasiones se realizaba de forma pública en plazas o

\footnotetext{
${ }^{86}$ Venegas, Fernando. 2005. "Entre el río y el mar: Concón, tierra de astilleros, pescadores y agricultores", en Elórtegui Sergio (ed) Las Dunas de Concón, el desafío de los espacios silvestres urbanos., Viña del Mar, p. 79.

87 Orellana Rivera, María Isabel. 2010. Una mirada a la escuela chilena, Santiago, p. 39.

88 Orellana Rivera, María Isabel. 2009. Cultura, ciudadanía y sistema educativo: cuando la escuela adoctrina. Dirección de Bibliotecas, Archivos y Museos - Museo de la Educación Gabriela Mistral, Santiago, LOM Ediciones.

89 Orellana Rivera, María Isabel y de la Jara, Irene. 2008. "Mobiliario y material escolar: el patrimonio de lo cotidiano", Vol III, Itinerario y memoria del Bicentenario, Archivo visual del Museo de la Educación Gabriela Mistral. DIBAM, MAVAL, p. 120.
} 
frente a iglesias ${ }^{90}$. Es claro que el sentido del castigo físico -a excepción del dolor que sería idéntico hoy- no se percibía de la forma brutal que lo ven nuestros ojos. Si no más bien como una medida prudente y fácil de memorizar que recrea la piedad católica de la época y los argumentos paternales de Dios. Los resabios de este devenir histórico aún se mantienen y los conceptos aprendidos en el cuerpo de los más viejos, han sido, por decirlo de un modo elegante, bien aprendidos.

Así como el primer acento de la escuela estuvo en la religión y la evangelización del salvaje, y el segundo periodo con el nacimiento de la república en "la guerra", -con unos cortos periodos de ideales liberales aplastados por gobiernos dictatoriales- el acento de la escuela de hoy, ¿dónde estaría? ¿Qué individuos forma hoy la escuela en Chile? La respuesta para el presente no es alentadora. El acento de hoy, así como lo fue la religión y la guerra en el pasado, es "un hombre para el mercado". Un hombre productivo, con altas metas respecto a la acumulación de capital (exitoso) -y por ende un buen consumidor-competitivo e individualista. El conocimiento no es un bien en sí mismo, es poder aplicado. $Y$ es frecuente la pregunta de los estudiantes de hoy en el aula... ¿Y “esto" para qué me va a servir? Los saberes inútiles que dan sentido al hombre son excluidos de la escuela y las disciplinas menos relacionadas con un objetivo productivo futuro decrecen o desaparecen del aula. El aula misma sigue teniendo atmósferas de violencia ${ }^{91}$, conceptualizada hoy en el bullying y que no es otra cosa que el resultado del pensamiento individual representado en "yo no soy otro tú" que tiene antecedente en "el miedo al otro" 92 , que autorizaría cualquier forma de dominación y privación con tal de una seguridad ilusoria. Los ideales anteriores sobre ser un buen hijo de Dios, luego un buen soldado y un buen ciudadano hoy han sido cambiados por el éxito individual. El discurso de interés público ha sido atrofiado por décadas de un adoctrinamiento neoliberal donde el mercado es lo que regula la sociedad y no al revés ${ }^{93}$. Un simple ejemplo es la jerarquización actual de las asignaturas respecto de cuáles son las más importantes para un futuro. ¿Qué tipo de futuro? Según Wubbena: "Aunque bajo la dictadura de Pinochet, Chile fue uno de los primeros países en adoptar reformas neoliberales, también se ha convertido en uno de los primeros países en comenzar a abandonar las reformas neoliberales para la educación

\footnotetext{
${ }^{90}$ Frontaura, José. 1892. Noticias históricas sobre las escuelas públicas de Chile a fines de la era colonial. Imprenta Nacional, Santiago de Chile.

${ }^{91}$ Neut, Pablo. 2017. "Las violencias escolares en el escenario educativo chileno. Análisis crítico del estado del arte" en Calidad en la Educación, $N^{\circ} 46$, Santiago, pp. 222-247.

92 Lechner, Norbert. 2002. Las sombras del mañana. La dimensión subjetiva de la política, Santiago, LOM.

93 "pareciera ser que el mercado educativo no ha resultado ser sólo una "lógica de mercado" y que el verdadero desafío comprensivo es entender que ha terminado siendo un "ethos de mercado", lo que significa finalmente que la lógica se ha hecho vida en el sistema escolar mismo" Retamal, J., \& González, S. De la microviolencia al clima escolar: Claves de comprensión desde el discurso de profesores de escuelas públicas de Santiago. Psicoperspectivas, 18(1), 1-15.
} 
(aun cuando las reformas educativas orientadas al mercado permanecen en la cima de la agenda política en países como Estados Unidos)" ${ }^{\prime 94}$.

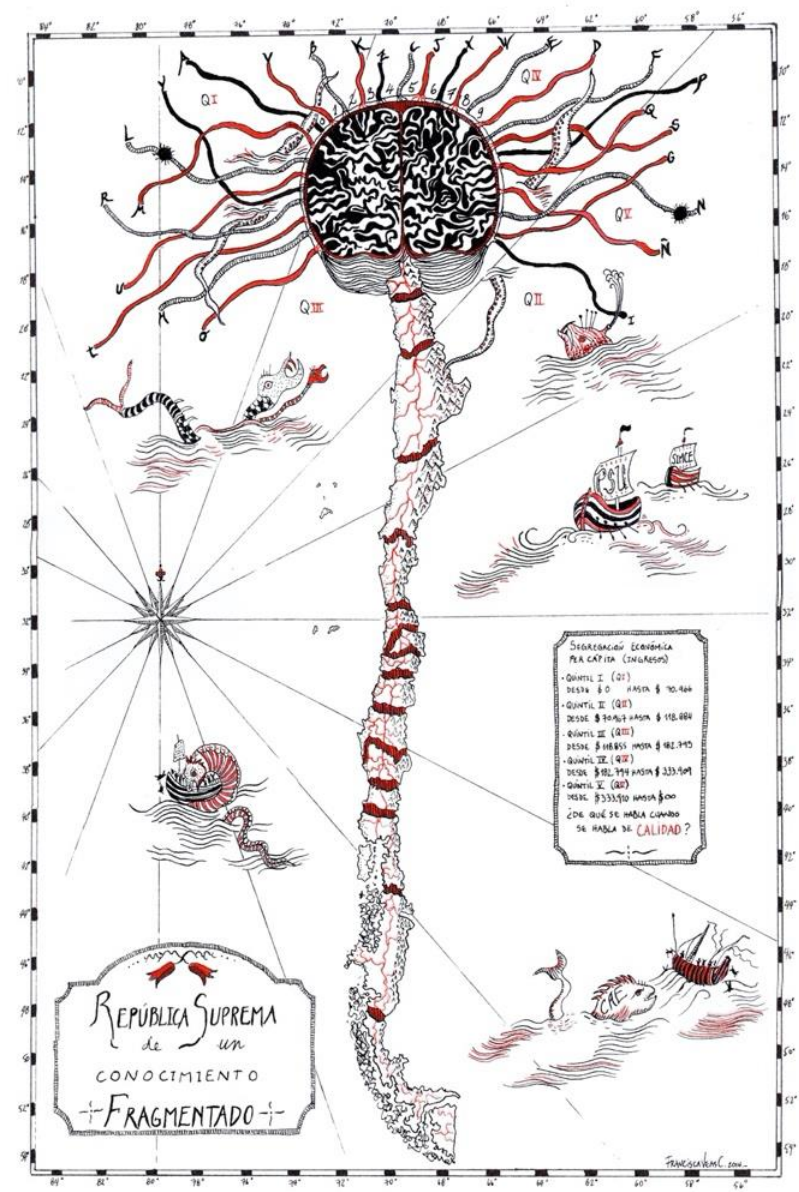

Figura 1. llustración de Francisca Veas: "El modelo de educación chileno es un desastre, favorece la segregación y no invierte los recursos en quienes más lo necesitan. Esta es una invitación a reflexionar sobre la situación de la educación chilena. Creemos necesario abrir espacios de reflexión y difusión sobre el derecho a la educación y a debatir de cómo nos gustaría que fuese." Exposición “Educasión Shilena” Tienda/Galería LoBa - Valparaíso/Junio 2014. https://franciscaveas.cl/expo-educasion-shilena-tiendagaleria-loba-valparaiso-2014/

Ya ha sido extensamente planteada la "necesidad y posibilidad de construir una nueva lógica educacional, basadas en la reflexividad, el desarrollo del espíritu crítico, el accountability inteligente y la formación integral" ${ }^{95}$ ¿Se avisora así una nueva vía hacia una escuela activa o

\footnotetext{
94 Wubbena, Zane. 2017. "A pedagogy for space: Visually framing the 2011 Chilean student movement", en Policy Futures in Education, vol.15, №4 1-21.

${ }^{95}$ Villalobos y Quaresma op. cit.
} 
paidocéntrica? Los alcances y proyecciones de una propuesta de educación popular inspirada en la visión de Paulo Freire, por otra parte, quedarán para una futura comunicación ${ }^{96}$.

\section{Conclusiones}

El recorrido del cuerpo en el aula fijado en los cronotopos construidos históricamente nos muestra los cambios, tensiones y órdenes instalados para configurar la relación educativa. La escuela fue modificando sus técnicas y conocimientos, así como la visión de la relación de los estudiantes con el entorno de aprendizaje; cuya imagen de poder luego de constituirse y reforzarse como un signo de saber de la mano del modelo de la República, pasaría a ser luego un instrumentador utilitario de una relación con arreglo a fines y mediada por la economía de mercado durante este siglo.

En los albores de Chile, como seguramente en el resto de América, el cronotopo del aula y el cuerpo en su dimensión biológica sufrió de las mayores precariedades. El frío, la humedad, el hambre y la falta de insumos, se sumó a una aún incipiente comprensión de la relación entre las condiciones de bienestar orgánico y el aprendizaje. El tiempo de permanencia en el aula fue más corto pues se requería a los jóvenes en la dimensión del trabajo. La mano de obra infantil no fue un tema cuestionable hasta entrado el siglo XX y la introducción de "la campana" que reguló el tiempo, no apareció en función del descanso sino para recordarle al profesor el derecho al uso de los menores en el ámbito doméstico. Durante el segundo periodo hubo avances en la forma en que se recibía al cuerpo a través de mejoras en el mobiliario y a mediados del siglo XIX, gracias a las escuelas preceptoras, las clases de educación generan un cambio cualitativo respecto al cuerpo que aprende: pudo salir del aula a un "aula exterior". Anhelo que bajo las ideas de Dewey trató de expandirse hacia una enseñanza activa con la reforma de 1928, pero se desaceleró rápidamente durante el período de Ibañez. ¿Qué ocurrió, por qué se desatendió tan oxigenante acción pedagógica? Esta pregunta es importante si vemos que en ese periodo las clases en terreno igual se ejercieron desde las propias comunidades de base. El cuerpo en el aula, entrado el siglo XX, como en una máquina del tiempo retrocede a condiciones profundamente inorgánicas. Los esfuerzos de masificación, municipalización bajo una lógica subsidiaria y todo esto bajo el contexto reinante del mercado, trajo otra vez una precarización del cuerpo. Enormes mallas de contenidos, extensos tiempos en la escuela, súpertecnologización del aprendizaje, sumado a trabajo escolar en el hogar (tarea para la casa), han atrapado y moldeado el cuerpo en función de las aspiraciones de un Estado que atiende las señales del mercado y al joven que se prepara para enfrentarlas.

\footnotetext{
96 Bustos, Luis; Oyarzún, Eugenio; Órdenes, David; et al. 2013. Somos Andando: Prácticas, caminos y saberes para construir Educación Popular hoy. Santiago, Quimantú.
} 
Durante el primer periodo, la escuela respecto del aula y el cuerpo frente al cuerpo del otro se encargó de marcar las diferencias y acentuar los valores predominantes entre los jóvenes. El aula era para unos pocos y esos pocos estaban preseleccionados desde la cuna. La escuela debía ser "blanca, católica y masculina". Las "niñas" no conocieron las aulas hasta la mitad del siglo XIX y algo tan natural hoy como son las escuelas mixtas fue un invento del siglo XX. Pero para los afortunados que pudieron entrar al aula con otros, también hubo mecanismos internos que aseguraban que los "más aventajados" fueran, de alguna manera, alejados de los "menos aventajados"; esto por una distribución que los segregaba espacio-temporalmente dentro del aula. Esta segregación hoy persiste. Ya no es una escuela blanca, católica y masculina, pero los efectos sobre una educación entregada al mercado, generaron hoy en Chile, entre otras consecuencias y dicho en palabras simples: "escuelas para pobres" y "escuelas para ricos". Esto en el primer cuarto del siglo XIX es una realidad social de violenta inequidad, insostenible y génesis primordial de la revuelta social.

En los primeros impulsos de la escuela relativos al aula y el cuerpo como sujeto frente a sí mismo, lo primordial por aprender fue ser un buen católico a como diera lugar, esto no por una particular piedad con el alma del sujeto, sino más bien por la construcción de un vasallo obediente. Luego el amor a la bandera y la formación para la guerra entró en escena pero igual que lo anterior, más que amor patriota, el Estado persiguió tener un contingente de jóvenes prontos para la primera línea para proteger los intereses de un Estado oligarca. Estas motivaciones constituyeron un aula que contaba con "formas" punitivas para lograr estos objetivos si la palabra no daba resultado. "La letra con sangre entra", es un eslogan que duró hasta hace no muy poco. Hoy, ya desaparecidas estas dolorosas prácticas, el sujeto dependiendo de la atmósfera de cada escuela y con suerte librándose del bullying, lucha con los problemas internos traídos por una enseñanza para el éxito individual.

Recogiendo lo que nos aporta el cronotopo del aula, la escuela tendría hoy una fuerte y paradojal misión: proteger a sus alumnos de las motivaciones sociales y del propio Estado que se "cuadra" (se adapta) en orden a lo que requiere el mercado. Esta hegemonía de la visión de mercado impone masificación, pero al mismo tiempo segregación, generando no obstante la percepción de que todos participan de una suerte de equidad monocroma frente al proceso educativo. Se precisa una reflexión profunda sobre la biopolítica, que se exprese en cada etapa y que se refuerce en las relaciones en el aula a través de un conjunto de dispositivos y estrategias que consideren tanto la interacción, la política y los horizontes propios del aprender humano.

Los cambios en curso, surgidos a partir del movimiento popular de 2019 y refrendado en el plebiscito de octubre 2020, alimentan la esperanza de lograr que la escuela y su núcleo del aula resguarden activamente el anhelo social primordial representado en la frase "yo soy otro tú". 
Ello implica el desafío de recuperar los espacio-tiempos relacionales dentro de la comunidadsociedad. Para ello es vital que el aula sea refugio primario de la diversidad, justicia y equidad.

\section{Bibliografía}

Alam, Florencia. 2016. "Civilización/barbarie en los manuales de historia del secundario", en Nómadas. Revista Crítica de Ciencias Sociales y Jurídicas, № 16, Buenos Aires, pp. 1-9.

Altinok, Nadir, Angrist, Noam \& Patrinos, Harry. 2018. “Global Data Set on Education Quality (19652015)", en Policy Research Working Paper, $N^{\circ} 8314$, Washington, DC. (C) World Bank. Disponible en: https://openknowledge.worldbank.org/handle/10986/29281 (Consultado el 08 de junio de 2020)

Arancibia, Leticia. 2011. "El imaginario autoritario en la escuela secundaria durante la transición democrática en Chile" en Revista Análisis, № 12, Vol. I, pp. 97-119. Disponible en: https://revistas.upr.edu/index.php/analisis/article/view/10774 (Consultado el 08 de julio de 2020)

Bajtín, Mijaíl. 1989. Teoría y estética de la novela, Madrid, Taurus.

Bajtín, Mijaíl. 1990. Estética de la creación verbal, México, Siglo XXI.

Bloome, David, Beierle, Marlene, Grigorenko, Margaret \& Goldman, Susan. 2009. "Learning over time: Uses of intercontextuality, collective memories, and classroom chronotopes in the construction of learning opportunities in a ninth-grade language arts classroom" en Language and Education, $\mathrm{N}^{\circ} 23$, Vol. IV, London, pp. 313-334.

Brown Raymond \& Peter Renshaw. 2006. "Positioning Students as Actors and Authors: A Chronotopic Analysis of Collaborative Learning Activities" en Mind, Culture and Activity, Nㅜㄴ 13 , Vol. III, London, pp. 247-259.

Carrillo, Juan José. 2010. "El neoliberalismo en Chile: entre la legalidad y la legitimidad: Entrevista a Tomás Moulián" en Perfiles Latinoamericanos, Nㅜ 35, Vol. 18, Ciudad de México, pp. 26-35.

Cox, Cristián. 1985. "Hacia la elaboración de consensos en política educacional: actas de una discusión", Santiago, CIDE. Disponible en: http://repositorio.uahurtado.cl/handle/11242/8759 (Consultado 17 de junio 2020)

Dantier, Bernard. 1999. Séparation ou désintégration de l'école?, Montreal, L'Harmattan.

Egaña, María Loreto. 2000. La educación primaria popular en el siglo XIX en Chile: una práctica de política estatal, Santiago, LOM Ediciones.

Elías, Norbert. 1973. La Civilisation des moeurs, Paris, Calmann-Lévy.

Elías, Norbert. 1974. La Société de Cour. Paris, Calmann-Lévy.

Frontaura, José. 1892. Noticias históricas sobre las escuelas públicas de Chile a fines de la era colonial, Santiago, Imprenta Nacional.

Foucault, Michel. 1992. Microfísica del poder, Madrid, La Piqueta.

Foucault, Michel. 1998. Vigilar y castigar, Madrid, Siglo XXI.

Foucault, Michel. 2007. Nacimiento de la Biopolítica. Curso en el Collège de France: 1978-1979, Buenos Aires, Fondo de Cultura Económica.

González, Jorge, Preiss, David \& San Martín, Ernesto. 2008. “Evaluando el discurso docente: Desarrollo de un modelo de Rash a partir de la evidencia audiovisual de profesores chilenos de primer ciclo de educación básica en el área de lenguaje" en Revista Iberoamericana de Evaluación Educativa, № 1 , Vol II, Madrid, pp. 138-147.

Holquist, Michael. 1982. "Bakhtin and Rabelais: Theory as praxis" en Boundary N 1/2, Vol. 11, Durham, pp. 5-19. 
Jaksic, Iván \& Serrano, Sol. 2000. “El poder de las palabras: la iglesia y el estado liberal ante la difusión de la escritura en el Chile del siglo XIX" en Historia (Santiago), $\mathrm{N}^{\circ} 33$, Santiago. Disponible en: http://dx.doi.org/10.4067/S0717-71942000003300010 (Consultado el 06 de mayo de 2020).

Labarca, Amanda. 1939. Historia de la Enseñanza en Chile, Santiago, Editorial Universidad de Chile. Lechner, Norbert. 2002. Las sombras del mañana: La dimensión subjetiva de la política, Santiago, LOM Ediciones.

Magendzo, Abraham \& Gazmuri, Consuelo. 1981. "El control autoritario expresado en las circulares del Ministerio de educación en el periodo 1973-1981" en Núñez, Iván (ed.). Las transformaciones educacionales bajo el régimen militar, Santiago, PIIE, pp. 461-477.

Manzi, Jorge, Strasser, Katherine, San Martin, Ernesto \& Contreras, Dante. 2008. Quality of education in Chile: final report of the Interamerican Development Bank Project, Washington, D.C. Disponible en: http://mapeal.cippec.org/wp-content/uploads/2014/06/Quality-of-Education-in-Chile.pdf (Consultado el 19 de julio de 2020).

Mauss, Marcel. 2013. Sociologie et anthropologie, París, PUF.

Memoria chilena. 2018. El Ministerio de Educación y el Estado docente (1927-2006). Reforma Educacional iniciada en 1965. Disponible en http://www.memoriachilena.gob.cl/602/w3-article97353.html (Consultado el 09 de julio de 2020).

Moss, Peter. 2014. Transformative Change and Real Utopias in Early Childhood Education: A Story of Democracy, Experimentation and Potentiality, New York, Routledge.

Muntañola, Josep. 2007. Las Formas del Tiempo I: Arquitectura, educación y sociedad, Badajoz, Ed. @becedario.

Neut, Pablo. 2017. "Las violencias escolares en el escenario educativo chileno. Análisis crítico del estado del arte" en Calidad en la Educación, N 46, Santiago, pp. 222-247.

Núñez, Iván. 2003. La ENU entre dos siglos. Ensayo histórico sobre la Escuela Nacional Unificada, Santiago, LOM Ediciones y Centro de Investigaciones Diego Barros Arana.

Núñez, Iván. 1984. Las transformaciones educacionales durante el régimen militar, Santiago, PIIE. OECD. 2016. Trends Shaping Education 2016, OECD Publishing. Disponible en: http://www.oecd.org/education/ceri/Spotlight8-Inequality.pdf (Consultado el 23 de julio de 2020). OECD. 2017. OCDE Revisiones de recursos escolares: Chile 2017. Disponible en: https://doi.org/10.1787/9789264287112-es (Consultado el 16 de julio de 2020).

OECD. 2018. Panorama de la educación 2017: Indicadores de la OCDE, Fundación Santillana, Madrid. Disponible en https://doi.org/10.1787/eag-2017-es. (Consultado el 23 de julio de 2020).

OCDE. 2020. Inegalité de revenu (indicateur). Disponible en: https://doi: 10.1787/37e2ea85-fr (Consultado el 21 de julio de 2020).

Orellana, María Isabel \& De la Jara, Irene. 2008. Mobiliario y material escolar: el patrimonio de lo cotidiano, Vol III, Serie: Itinerario y memoria del Bicentenario. Archivo visual del Museo de la Educación Gabriela Mistral, Santiago, DIBAM, MAVAL.

Orellana, María Isabel. 2010. Una mirada a la escuela chilena: entre la lógica y la paradoja, Santiago, DIBAM.

Picazo, Inés. 2010. "La metamorfosis de la regulación pública en la educación escolar en Chile: hacia un estado post-neoliberal" en Pensamiento Educativo, N 46, Valdivia, pp. 63-91.

Preiss, David. 2011. "Patrones instruccionales en Chile: La Evidencia de la Evaluación Docente" en Manzi, Jorge \& González, Rosa (eds.). La Evaluación Docente en Chile, Santiago, MIDE UC, pp. 209212.

Radovic, Darinka \& Preiss, David. 2010. “Patrones de discurso observados en el aula de matemática de segundo ciclo básico en Chile” en Psykhe, №19, Vol. II, Santiago, pp. 65-79. 
Rajala, Antti, Hilppö, Jaakko, Lipponen, Lasse \& Kumpulainen, Karen. 2013. “Expanding the chronotopes of schooling for the promotion of students' agency" en Erstad, Ola \& Sefton-Green, Julian (eds.). Identity, community, and learning lives in the digital age, Cambridge, Cambridge University Press, pp. 107-125.

Ritella, Giuseppe \& Ligorio, Beatrice. 2016. "Investigating chronotopes to advance a dialogical theory of collaborative sensemaking” en Culture \& Psychology, N²2, Vol. II, Aalborg, pp. 216-231.

Ritella, Giuseppe, Rajala, Antti \& Renshaw, Peter. 2020. "Using chronotope to research the space-time relations of learning and education: Dimensions of the unit of analysis" en Learning, Culture and Social Interaction. Disponible en: https://doi.org/10.1016/j.Icsi.2020.100381 (Consultado el 20 de junio de 2020).

Rivkin, Mary. 1998. "Happy Play in Grassy Places: The Importance of the Outdoor Environment in Dewey's Educational Ideal", en Early Childhood Education Journal, N³, Vol. 25, Pittsburgh, pp. 199202.

Rousseau, Jean-Jacques. 2003. El contrato social o Principios de derecho político. Buenos Aires, Losada.

Ruiz, Carlos. 2012. "La República, El Estado y El Mercado en Educación” en Revista de filosofía, N 68, pp. 11-28. Disponible en: https://dx.doi.org/10.4067/S0718-43602012000100003 (Consultado el 15 de julio de 2020).

Säljö, Roger. 2009. "Learning, theories of learning, and units of analysis in research" en Educational Psychologist, $\mathrm{N}^{\circ} 44$, Vol. III, North Carolina, pp. 202-208.

Salvat, Pablo. 2001. "La lucha por la reconciliación en Chile: una aproximación desde la dialéctica del reconocimiento y la ética dialógica” en Lira, Elizabeth, Loveman, Brian, Mifsud, Tony \& Salvat, Pablo (eds.). Historia política y ética de la verdad en Chile, 1891-2001. Reflexiones sobre la paz social y la impunidad, Santiago, LOM, pp. 114-143.

Superintendencia de Educación, Oficina Técnica. 1965. Recopilación de antecedentes acerca de la historia y la evolución de la educación en Chile: informe a la petición formulada por la Embajada de Chile en Francia (París). Disponible en: http://www.memoriachilena.gob.cl/602/w3-article64081.html (Consultado el 06 de mayo de 2020).

Tahon, Marie Blanche. 1999. "Le micro-ondes, le privé et le domestique: rapports sociaux de sexe", en Recherches sociologiques, $\mathrm{N}^{\circ} 30$, Vol. III, Louvain, pp. 87-114.

Tarcov, Nathan. 1984. Locke's Education for Liberty, Chicago, U of Chicago Press.

Times Press. 2019. Why Chile's SATs Have Become the New Frontline of Inequality Protests. New York. Disponible en: https://time.com/5770308/chile-student-protests/ (Consultado el 13 de Julio de 2020).

Van Eijck, Michiel \& Roth, Wolff Michael. 2010. "Towards a chronotopic theory of place in place-based education" en Cultural Studies of Science Education, N 5, Vol. IV, New York, pp. 869-898.

Venegas, Fernando. 2005. "Entre el río y el mar: Concón, tierra de astilleros, pescadores y agricultores", en Elórtegui, Sergio (ed.). Las Dunas de Concón, el desafío de los espacios silvestres urbanos, Viña del Mar, Taller La Era, pp. 74-85.

Wubbena, Zane. 2017. "A pedagogy for space: Visually framing the 2011 Chilean student movement", en Policy Futures in Education, N¹5, Vol. IV, (0), Auckland, pp. 460-480. 